\title{
Influence of the killing method of the black soldier fly on its lipid composition
}

\author{
Augusta Caligiani $^{\mathrm{a}, *}$, Angela Marseglia ${ }^{\mathrm{a}}$, Alessia Sorci ${ }^{\mathrm{a}}$, Francesca Bonzanini ${ }^{\mathrm{a}}$, Veronica Lolli $^{\mathrm{a}}$, \\ Lara Maistrello ${ }^{\mathrm{b}}$, Stefano Sforza ${ }^{\mathrm{a}}$ \\ ${ }^{a}$ Department of Food and Drug, University of Parma, Parma, Italy \\ ${ }^{\mathrm{b}}$ Department of Life Sciences, University of Modena and Reggio Emilia, Reggio Emilia, Italy
}

A R T I C L E I N F O

\section{Keywords:}

Black soldier fly

Acylglicerols

Sterols

Free fatty acids

Blanching

Killing

\begin{abstract}
A B S T R A C T
Black soldier fly (BSF, Hermetia illucens) represents a valuable source of biomolecules and it also constitutes an economic way to valorise residual biomasses. BSF prepupae contain high amounts of lipids (37\% DM basis). The present investigation aimed at studying the composition of BSF lipids and the effect of killing/storage on their quality. The main fatty acid was lauric acid, sterols were represented primarily by beta-sitosterol and campesterol. Global fatty acid and sterol profiles, determined by GC-MS, were only slightly affected by the killing procedure, while lipid classes distribution, determined by ${ }^{1} \mathrm{H}$ NMR, strongly changed. Prepupae killed by freezing showed a drastic reduction of acylglycerols during storage and a relevant release of free fatty acids, likely due to activation of lipases. On the contrary, prepupae killed by blanching have a stable lipid fraction constituted mainly by triacylglycerols. Therefore, killing procedure strongly influences BSF oil composition and the potential applications.
\end{abstract}

\section{Introduction}

Entomophagy, the consumption of insects for food purposes, is conventionally practiced in many regions of the world, such as Asia, South America, Australia and Africa (Caparros Megido et al., 2013). In the last decades, the interest in insects as a food source strongly increased all over the world, primarily in connection with the perspectives of growing population. In 2050 the world population is estimated to reach 9 billion people, therefore there is a need to find sustainable food source for future food demands. Currently insects are not the main source of energy in any Countries, but they could complement in the future the traditional sources of protein and lipid.

Many insects, especially in the larvae/prepupae stages, have a high nutritive value, containing fats, proteins, vitamins, fibres and minerals (van Huis et al., 2013). The nutritional value is highly variable among the large number of edible insects (Kouřimská \& Adámková, 2016). Certain insect species contain high proportions of fat (Barroso et al., 2014; Ramos-Elorduy, 1997), thereby opening interesting possibilities for food applications, but also for other industrial purposes, as biodiesel production. The Black Soldier Fly (BSF) Hermetia illucens (Linnaeus, 1758) (Diptera, Stratiomiydae) is one of the insect species richest in lipids (Ramos-Bueno, González-Fernández, Sánchez-Muros-Lozano,
García-Barroso, \& Guil-Guerrero, 2016.), and is currently also of particular interest because of its high efficiency as bio-converter of organic waste and agricultural by-products (Diener, Studt Solano, Gutiérrez, Zurbrügg, \& Tockner, 2011). In the light of the new Regulation on Novel Foods (EU 2015/2283), edible insects are increasingly being introduced into the EU Countries. In parallel, several ways to process insects into food products and fractions are currently being explored, mainly to overcome the reluctance of some part of the population in eating whole insects. In fact, some studies evidenced that consumer have more willingness to eat insects when they are not visible in food (Balzan, Fasolato, Maniero, \& Novelli, 2016). Transformation of whole insects into meals, protein and other fractions for food/feed ingredients can be viewed as a necessary step to enhance the acceptability and the diffusion of insects. To address this point, fractionation strategies were recently developed to separate lipid, protein and chitin from BSF prepupae: (Caligiani et al., 2018). It turned out that lipids can be easily extracted from BSF prepupae by common solvent-based extraction procedures, and the separation of the lipid fraction is often a preliminary step during the preparation of high protein meal. The main application currently exploited for the utilization of BSF fat is the production of biodiesel (Li et al., 2011; Li et al., 2015), but a deeper investigation of BSF fat composition and properties could support the

\footnotetext{
* Corresponding author at: Department of Food and Drug, University of Parma, Parco Area delle Scienze 27A, 43124 Parma, Italy.

E-mail address: augusta.caligiani@unipr.it (A. Caligiani).
} 
exploitation of higher added value uses in the food/feed sector. From this point of view, data about the behaviour of the lipid fraction and the lipid classes distribution during BSF processing and storage are almost completely lacking.

The insect pre-processing, stabilization/killing methods are also important points. The European animal welfare Directive 98/58/EC for animal farming does not apply to insects, as they are non-vertebrate animals, leaving room to the most convenient methodologies. The most common killing procedure used is freezing, eventually followed by freeze-drying to increase stabilization (Vandeweyer, Lenaerts, Callens, \& Van Campenhout, 2017). Alternative ways for killing/stabilization still need to be explored, and thermal treatments look especially promising. For example, a common procedure employed mainly in vegetables and fruit processing is blanching, aimed at stopping enzymatic activity prior to further storage or processing (Fellows, 2009). Blanching was used for pre-treatment of Tenebrio molitor larvae, with the aim to reduce microbial load (Vandeweyer et al., 2017), but it has never been used for BSF killing/stabilization.

In this paper, two different killing methods (blanching or freezing) were compared to evaluate potential modifications in the lipid fraction. In particular, a detailed molecular profiling of lipid from BSF prepupae was assessed in terms of lipid classes distribution, fatty acid and sterol profiles.

\section{Materials and methods}

\subsection{BSF sampling and pre-treatments}

Samples of $H$. illucens prepupae were obtained by Smart Bugs s.s. (Ponzano Veneto, Italy). Their growing substrate consisted of vegetable residues: $50 \%$ corn flour zootechnical use (mill waste), $40 \%$ wheat bran, $10 \%$ alfa-alfa flour. Water was added to have $2 / 3$ dry diet and $1 / 3$ water. A first BSF sample was obtained frozen (BSF1 sample), half of it was stored frozen as whole prepupae at $-20{ }^{\circ} \mathrm{C}$ (BSF1fr) and the other half was grinded and freeze-dried (Liophilizer LIO 5P, International PBI Milan, Italy) until $10 \%$ residual moisture, then stored at $-20^{\circ} \mathrm{C}$ (BSF1lio). A second sample of BSF prepupae (BSF2 sample) was provided alive. One kilogram was killed by blanching for $40 \mathrm{~s}$ in hot water at $100^{\circ} \mathrm{C}$ (BSF2bl), and another kilogram by freezing at $-20^{\circ} \mathrm{C}$ (BSF2fr). All the samples were stored frozen at $-20{ }^{\circ} \mathrm{C}$ in ziplock bags until usage. BSF2bl and BSF2fr were analysed immediately after the pre-treatment (T0) and after two months of frozen storage (T1).

\subsection{Chemicals}

Diethyl ether, petroleum ether $\left(40-60{ }^{\circ} \mathrm{C}\right.$ boiling point fraction), potassium hydroxide, dichloromethane were from Carlo Erba (Milan, Italy); hexane, methanol, methyl pentacosanoate, 5-alpha-Cholestan-3beta-ol were purchased from Sigma-Aldrich (Milan, Italy), $\mathrm{N}, \mathrm{O}$-bis(trimethylsilyl)trifluoroacetamide (BSTFA) with $1 \%$ trimethylchlorosilane were purchased from Fluka.

\subsection{Lipid extraction}

Different methods for lipid extraction were tested and the results compared. To determine crude fat content $2 \mathrm{~g}$ of BSF prepupae were finely grinded and extracted using an automatized Soxhlet fat extractor (SER 148/3 VELP SCIENTIFICA, Usmate Velate, Italy) with diethylether $(60 \mathrm{~mL})$ as extraction solvent (AOAC, 2006). The same Soxhlet extraction was performed using petroleum ether. Lipids were also extracted with the method of Folch, Lees, and Sloane Stanley (1957), using dichloromethane instead of chloroform, as suggested by Cequier-Sanchez, Rodriguez, Ravelo, \& Zarate, 2008. BSF oil samples were kept at $-20{ }^{\circ} \mathrm{C}$ and in the dark until analysis.

\subsection{Determination of oil acidity}

BSF oil acidity was determined by titration of the oil dissolved in a mixture of methylene chloride/acetic acid using KOH 0.1 N. Methods was adapted from official method for acidity determination in vegetable oils (Berner, 1989), by expressing results as percentage of lauric acid, because it represents the most abundant in BSF fatty acids profile.

\subsection{Determination of fatty acids profile by GC-MS}

BSF fat was subjected to acidic and basic transmethylations separately, performed according to ISO 12966-2 (ISO, 2017), with slight modifications. For basic transmethylation, $100 \mathrm{mg}$ of the fatty residue were dissolved in hexane ( $5 \mathrm{~mL}$ ), added to $2 \mathrm{~mL}$ of $\mathrm{KOH} 5 \%$ in methanol and mixed vigorously for $5 \mathrm{~min}$. For acid-catalyzed transmethylation, $100 \mathrm{mg}$ of BSF fat were added to $0,5 \mathrm{~mL}$ of $\mathrm{H}_{2} \mathrm{SO}_{4} /$ methanol $(1: 15 \mathrm{v} / \mathrm{v})$ and heated for $3 \mathrm{~h}$ at $100{ }^{\circ} \mathrm{C}$. After cooling, $5 \mathrm{~mL}$ of hexane were added. For both samples, $500 \mu \mathrm{L}$ of the hexane phase was withdrawn and added to $100 \mu \mathrm{L}$ of internal standard methyl pentacosanoate. A dilution of this solution was performed to match the linearity range of the GC-MS instrument, by taking $50 \mu \mathrm{L}$ and diluting with $1000 \mu \mathrm{L}$ of $\mathrm{n}$ hexane. The solutions were split-injected $(1 \mu \mathrm{L})$ on a Thermo Scientific Trace 1300 gas-chromatograph (Thermo Scientific, Waltham, Massachusetts, USA) carrying a Supelcowax ms capillary column (Supelco, Bellafonte, USA) coupled to a Thermo Scientific Trace ISQ mass spectrometer (Thermo Scientific, Waltham, Massachusetts, USA). Content of each single fatty acid was calculated in relation to the concentration of the internal standard, after calculating the response factors using the Supelco ${ }^{\circledR} 37$ Component FAME Mix (Sigma Aldrich, Saint Louis, MO, USA). Finally, results were expressed as relative percentage.

\subsection{Determination of sterols and other compounds of unsaponifiable fraction}

Unsaponifiable matter were extracted and silylated according to ISO 12228-1:2014 (ISO, 2014). $5 \mathrm{~g}$ of BSF oil and $100 \mathrm{~mL}$ of a $2.2 \mathrm{~N}$ potassium hydroxide solution in ethanol-water $(8: 2 \mathrm{v} / \mathrm{v})$ were put into a $250 \mathrm{~mL}$ flask; saponification was carried out by boiling and stirring the sample for $1 \mathrm{~h}$. After cooling, $100 \mathrm{~mL}$ of distilled water were added, and the sample transferred to a separating funnel and extracted 4 times with $50 \mathrm{~mL}$ of ethyl ether. The ether extracts were pooled into a separating funnel and washed with distilled water ( $50 \mathrm{~mL}$ each time), until the wash gave a neutral reaction. Then the wash water was removed, and the organic sample was dried with anhydrous sodium sulphate, filtered, taken to dryness and the residue weighed. The residue was dissolved in $100 \mu \mathrm{L}$ of 5-alfa-cholestan-3-beta-ol solution (internal standard, $520 \mathrm{ppm}$ in hexane) and silylated with $100 \mu \mathrm{L}$ of BSTFA $\left(1 \mathrm{~h}, 60^{\circ} \mathrm{C}\right)$. The composition of the unsaponifiable was determined by injecting $1 \mu \mathrm{L}$ of the silylated solutions in the GC-MS system. GC-MS analysis was performed on a $6890 \mathrm{~N}$ gas chromatograph coupled to an $5973 \mathrm{~N}$ mass selective detector (Agilent technologies, Santa Clara, CA) with a DB5 (J \&W) capillary column (temperature: $80^{\circ} \mathrm{C}$ for $2 \mathrm{~min}, 15^{\circ} \mathrm{C} / \mathrm{min}$ until $280^{\circ} \mathrm{C}, 280^{\circ} \mathrm{C}$ for $20 \mathrm{~min}$ ). Injection mode: split. Acquisition mode: scan ( $m / z$ 40-550). Unsaponifiable components were quantified by means of the internal standard (5-alfa-cholestan-3-beta-ol), according to Caligiani, Bonzanini, Palla, Cirlini, \& Bruni, 2010.

\subsection{Determination of lipid class distribution by ${ }^{1} \mathrm{H} N M R$}

${ }^{1} \mathrm{H}$ NMR analysis was performed on the same samples analysed for fatty acid and sterol profiles and also on BSF1 and BSF1lyo samples after 6 months of storage at $-20^{\circ} \mathrm{C}$. Lipids from BSF1 sample were extracted by Soxhlet from the whole insect (BSF1fr whole) or after grinding (BSF1fr). BSF lipids $(50 \mathrm{mg}$ ) were diluted in $0.8 \mathrm{~mL}$ of deuterated chloroform $\left(\mathrm{CDCL}_{3}\right)$ in a $5 \mathrm{~mm}$ glass tube for NMR analysis. NMR spectra were registered on a Bruker Avance III $400 \mathrm{MHz}$ NMR 
Spectrometer (Bruker BioSpin, Rheinstetten, Karlsruhe, Germany) operating at a magnetic field-strength of $9.4 \mathrm{~T}$. Spectra were acquired at $298 \mathrm{~K}$, with $32 \mathrm{~K}$ complex points, using a $90^{\circ}$ pulse length and $3 \mathrm{~s}$ of relaxation delay (d1). 128 scans were acquired with a spectral width of $9595.8 \mathrm{~Hz}$ and an acquisition time of $1.707 \mathrm{~s}$. The relaxation delay and acquisition time allow the complete relaxation of the protons, allowing their integrals for quantitative purposes. Table S1 of the supplementary material reports the identification of the main signals assigned in the BSF lipid spectrum, grouped by classes, and highlighting with letters those integrated for the quantification. The whole zone ranging from 0.87 to $2.90 \mathrm{ppm}$ plus signal centered at $5.35 \mathrm{ppm}$ were used as determinant indicative of total fatty acid moles, both free and bound. For the glycerol esters, the specific signals listed in Table S1 were integrated. Integrals were normalized for the number of hydrogen contributing to the specific signal (see Table S1). In the case of fatty acid integral, the mean number of hydrogen in fatty acids was inferred from the mean fatty acid composition obtained by gas chromatographic analysis, and it was found as 27.7.

The normalized areas obtained were converted as relative molar percentages. To determine the molar percentage of free fatty acids, the total fatty acid molar percentages was subtracted of the contribution of fatty acids bound to TG, DG and MG, according to the simple relation:

$[\mathrm{FFA}]=[\mathrm{TFA}]-(3[\mathrm{TG}]+2[\mathrm{DG}]+1[\mathrm{MG}])$

\subsection{Data analysis}

All data are presented in Tables 1, 2, 3, and 4 as mean and SD of three independent fat extractions and analyses. For each parameter, one-way ANOVA and post hoc Tukey-HSD tests were performed to detect statistically significant differences among the samples $(p<.05)$. All the statistical analyses were performed utilizing SPSS statistical software (IBM SPSS Statistics 25, IBM, New York, USA).

\section{Results and discussion}

\subsection{Yield of black soldier fly oil and oil acidity}

Sample BSF1, consisting of frozen BSF prepupae having been killed by freezing before reception in the laboratory, was used to test the effect of different extraction systems on BSF lipids. Automated extraction based on Soxhlet system was performed with both diethyl ether and petroleum ether, giving not significantly different yields (12.5-12.6\% fresh matter basis). These figures indicate a considerable lipid fraction, which confirms BSF as a good source of lipids, unlike other insect species with lower lipid content (Ramos-Bueno et al., 2016).

Fat extraction from BSF1 prepupae was also performed by the Folch method (Folch et al., 1957). Although it is generally recognized as a highly efficient method for extracting lipids from animal tissue, in this case it has low throughput, with a yield of lipid extracted significantly

Table 1

Yield of lipid extraction obtained with three different extraction systems and corresponding oil acidity, determined by titration with $\mathrm{KOH}$ and expressed as percentage of free lauric acid.

\begin{tabular}{|c|c|c|c|c|}
\hline & Method & Solvent & $\begin{array}{l}\text { Lipid Yield (\% fresh } \\
\text { matter)* }\end{array}$ & $\begin{array}{l}\text { Lipid acidity (\% free } \\
\text { lauric acid)* }\end{array}$ \\
\hline \multirow[t]{3}{*}{ BSF1 } & Soxhlet & Diethyl ether & $12.52 \pm 0.05 b$ & $80 \pm 1 c$ \\
\hline & Soxhlet & $\begin{array}{l}\text { Petroleum } \\
\text { ether }\end{array}$ & $12.6 \pm 0.5 b$ & $80 \pm 1 c$ \\
\hline & Folch & $\begin{array}{l}\mathrm{CH}_{2} \mathrm{Cl}_{2} / \\
\mathrm{CH}_{3} \mathrm{OH}(2: 1)\end{array}$ & $9.1 \pm 0.1 \mathrm{a}$ & $81.6 \pm 0.9 c$ \\
\hline BSF2fr & Soxhlet & Diethyl ether & $13 \pm 1 b$ & $18.3 \pm 0.5 b$ \\
\hline BSF2bl & Soxhlet & Diethyl ether & $13.3 \pm 0.8 b$ & $1.8 \pm 0.2 \mathrm{a}$ \\
\hline
\end{tabular}

* Values followed by different letters within one column are significantly different $(p<.05) ; n=3$. lower respect to Soxhlet methods (9.11\% of lipid extracted, Table 1). Soxhlet method was then chosen as most suitable for BSF lipid extraction, and applied also to BSF2bl and BSF2fr samples (samples of BSF prepupae either killed by freezing or blanching). The total amount of lipids for these samples (13.0-13.3\%) was not significantly different from BSF1 sample.

The low yield of lipids obtained by Folch method was tentatively explained by supposing the presence of acidic lipids (free fatty acids), which can be partly lost as fatty acid salts in the aqueous phase during Folch extraction. This hypothesis was tested by measuring the oil free acidity, and indeed, the free fatty acid amount was found to be surprisingly high for sample BSF1, reaching a striking $80 \%$ of free fatty acids. Also for BSF2fr the amount of free fatty acid was quite high (13\%), even if at levels not comparable with the ones found in the previous sample. BSF1 and BSF2fr samples have in common the killing method by freezing. On the other side, for sample BSF2bl, where prepupae were blanched before freezing, the amount of free fatty acids was basically negligible (Table 1 ). To the best of our knowledge, the high acidity of BSF oil has never been reported previously in the literature, even if the killing by freezing is by far the most widespread method for BSF larvae/prepupae. These preliminary data called for a deeper investigation about the oil composition and, mostly, on the effect of prepupae killing method and storage on the lipid fraction. To this aim, the detailed distribution of the various lipid classes, the fatty acid profile and the sterol profile were studied.

\subsection{Fatty acid profile}

Fatty acid profiles were determined on BSF2 samples (both blanched and frozen) immediately after killing (T0) and after a period of two months of storage at $-20^{\circ} \mathrm{C}$ (T1). Due to the high amount of free fatty acids demonstrated by acidity determination, the total fatty acid profile was determined by GC-MS after esterification by acidic methylation. In parallel, BSF oil samples were also analysed after transesterification by alkali methylation, to obtain the profile of bound fatty acids and to highlight possible selective release of specific fatty acids from triacylglycerols. Results are reported in Table 2.

GC-MS analysis allowed to identify short, medium and long chain fatty acids, in the range 9:0-22:0. The main fatty acid was by far represented by lauric acid (12:0), a medium chain fatty acid characteristic of coconut oil, accounting in all samples for $>40 \%$ of total fatty acids, reaching a peak of $75 \%$ in BSF2fr sample after two months of storage. Other saturated fatty acids present in significant amount were myristic (14:0), palmitic (16:0), stearic (18:0) and capric (10:0) acids. The most abundant polyunsaturated fatty acids (PUFAs) was linoleic acid (9c12c18:2) and minor amounts of its conjugated isomer (CLA, 9cis, 11trans) was also detected. This specific fatty acid composition can be influenced by the insect rearing substrate, but in general the data reported are in line with other studies, which also confirmed the abundance of medium chain saturated fatty acids (Leong, Kutty, Malakahmad, \& Tan, 2016; Li et al., 2016; Surendra, Olivier, Tomberlin, Jha, \& Khanal, 2016). Basic and acidic methylation for samples BSF2bl (T0 and T1) and for sample BSF2fr (T0) substantially gave similar relative profile of fatty acids, indicating that the distribution of glycerol-bound fatty acids and released (free) fatty acids are very similar. A completely different behavior was observed for sample BSF2fr after two months of storage (T1). This sample showed a dramatically different distribution of fatty acids when comparing the total with the bound fatty acid profile: the glycerol-bound fraction of BSF2fr T1 was found to be significantly richer in saturated fatty acids respect to the total one, (about $98 \%$ of saturated fatty acids vs $80 \%$ ). In particular, the amount of bound lauric acid increased from 45.6 to $75.9 \%$. These results indicate some selective hydrolytic reactions during storage of BSF2 sample not subjected to thermal treatment (blanching), suggesting a selective cleavage of unsaturated fatty acids by lipase enzymes. The lipase activity during frozen storage is a known phenomenon, for example in fish (Fidalgo, 
Table 2

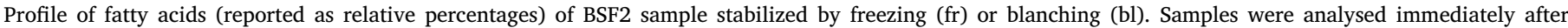

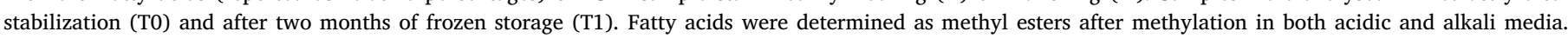
Coefficient of variations (CV\%) ranged from $2 \%$ to $8 \%$. Values followed by different letters within one row are significantly different ( $\mathrm{p}<.05$ ); $\mathrm{n}=3$.

\begin{tabular}{|c|c|c|c|c|c|c|c|c|}
\hline & BSF2fr T0 & BSF2fr T0 & BSF2fr T1 & BSF2fr T1 & BSF2bl T0 & BSF2bl T0 & BSF2bl T1 & BSF2bl T1 \\
\hline Methylation & Acid (total FA) & Basic (bound FA) & Acid (total FA) & Basic (bound FA) & Acid (total FA) & Basic (bound FA) & Acid (total FA) & Basic (bound FA) \\
\hline Fatty acid* & 1 & 2 & 3 & 4 & 5 & 6 & 7 & 8 \\
\hline 9:0 & $0.17 \mathrm{~d}$ & $0.07 \mathrm{~b}$ & $0.15 d$ & $0.02 \mathrm{a}$ & $0.11 \mathrm{c}$ & $0.16 \mathrm{~d}$ & $0.01 \mathrm{a}$ & $0.10 \mathrm{c}$ \\
\hline $10: 0$ & $1.63 \mathrm{~b}$ & $2.45 c$ & $1.90 \mathrm{~b}$ & $0.74 \mathrm{a}$ & $2.48 \mathrm{c}$ & $2.60 \mathrm{c}$ & $1.83 \mathrm{~b}$ & $2.44 \mathrm{c}$ \\
\hline 11:0 & $0.07 \mathrm{~b}$ & $0.03 \mathrm{~b}$ & $0.07 \mathrm{~b}$ & $0.01 b$ & $0.05 b$ & $0.07 \mathrm{~b}$ & $1.71 \mathrm{a}$ & $0.05 b$ \\
\hline $12: 0$ & 48.98 & $44.16 \mathrm{~b}$ & $45.60 \mathrm{bc}$ & $75.93 d$ & $47.09 c$ & $40.17 a$ & $47.3 c 5$ & $40.03 a$ \\
\hline $14: 0$ & $14.43 b c$ & $15.79 d$ & $14.52 \mathrm{bc}$ & $12.99 \mathrm{a}$ & $15.84 d$ & $15.19 \mathrm{~cd}$ & $14.12 \mathrm{~b}$ & $14.87 b c$ \\
\hline 12-Me-13:0 & $0.10 \mathrm{de}$ & $0.07 b c$ & $0.12 \mathrm{ef}$ & $0.03 a$ & $0.08 \mathrm{~cd}$ & $0.14 \mathrm{f}$ & $0.05 \mathrm{ab}$ & $0.09 \mathrm{~cd}$ \\
\hline $9 c-14: 1$ & $0.25 b$ & $0.15 b$ & $0.24 b$ & $0.03 b$ & $0.16 \mathrm{~b}$ & $0.29 \mathrm{~b}$ & $2.75 \mathrm{a}$ & $0.18 b$ \\
\hline $15: 0$ & $0.08 c$ & $0.05 b$ & $0.09 \mathrm{~cd}$ & $0.02 \mathrm{a}$ & $0.05 b$ & $0.10 \mathrm{~d}$ & $0.03 a$ & $0.06 \mathrm{~b}$ \\
\hline 12-Me-14:0 & $0.09 \mathrm{~d}$ & $0.06 \mathrm{bc}$ & $0.11 \mathrm{de}$ & $0.06 \mathrm{a}$ & $0.06 \mathrm{c}$ & $0.13 e$ & $0.09 \mathrm{~b}$ & $0.08 \mathrm{c}$ \\
\hline 13-Me-14:0 & $0.13 d$ & $0.08 b c$ & $0.15 \mathrm{de}$ & $0.04 a$ & $0.10 \mathrm{c}$ & $0.17 \mathrm{e}$ & $0.07 b$ & $0.10 \mathrm{c}$ \\
\hline $9 c-15: 1$ & $0.04 c$ & $0.02 \mathrm{a}$ & $0.05 d$ & n.d. & $0.02 \mathrm{a}$ & $0.04 c$ & n.d. & $0.03 \mathrm{~b}$ \\
\hline $16: 0$ & $14.40 \mathrm{~cd}$ & $16.30 \mathrm{e}$ & $15.54 \mathrm{de}$ & $8.21 \mathrm{a}$ & $14.26 c$ & $13.79 b c$ & $12.75 b$ & $16.62 \mathrm{e}$ \\
\hline 14-Me-15:0 & $0.22 \mathrm{~d}$ & $0.14 \mathrm{~b}$ & $0.25 d$ & $0.07 a$ & $0.13 b$ & $0.29 \mathrm{e}$ & n.d. & $0.18 c$ \\
\hline $9 c-16: 1$ & $2.31 \mathrm{~b}$ & $2.58 \mathrm{bc}$ & $2.23 b$ & $0.14 \mathrm{a}$ & $2.39 b c$ & $3.42 \mathrm{~d}$ & $2.01 \mathrm{~b}$ & $2.99 \mathrm{~cd}$ \\
\hline $17: 0$ & $0.07 \mathrm{~cd}$ & $0.04 \mathrm{~b}$ & $0.09 \mathrm{ef}$ & $0.02 \mathrm{a}$ & $0.08 \mathrm{de}$ & $0.10 \mathrm{f}$ & n.d. & $0.06 c$ \\
\hline 14-Me-16:0 & $0.04 d$ & $0.02 b$ & $0.04 \mathrm{~d}$ & $0.01 \mathrm{a}$ & $0.04 \mathrm{~d}$ & $0.05 \mathrm{e}$ & n.d. & $0.03 c$ \\
\hline 15-Me-16:0 & $0.09 \mathrm{~d}$ & $0.06 \mathrm{bc}$ & $0.11 \mathrm{e}$ & $0.03 a$ & $0.05 b$ & $0.12 \mathrm{e}$ & n.d. & $0.07 \mathrm{c}$ \\
\hline $9 c-17: 1$ & $0.07 \mathrm{ab}$ & $0.04 a$ & $0.08 \mathrm{~b}$ & n.d. & $0.05 \mathrm{ab}$ & $0.08 \mathrm{~b}$ & $0.36 c$ & $0.06 \mathrm{ab}$ \\
\hline $17: 1$ & $0.07 a b c$ & $0.05 a$ & $0.09 \mathrm{bc}$ & n.d. & $0.05 a$ & $0.10 \mathrm{c}$ & $0.31 \mathrm{~d}$ & $0.06 \mathrm{ab}$ \\
\hline $18: 0$ & $1.31 \mathrm{~d}$ & $1.21 \mathrm{~cd}$ & $1.18 \mathrm{~cd}$ & $0.59 a$ & $0.96 b c$ & $1.45 \mathrm{~d}$ & $0.89 \mathrm{~b}$ & $1.27 \mathrm{~d}$ \\
\hline $9 c-18: 1$ & $6.57 \mathrm{bc}$ & $7.98 \mathrm{~d}$ & $7.79 \mathrm{~d}$ & $1.06 \mathrm{a}$ & $6.79 c$ & $9.88 \mathrm{f}$ & $6.21 b$ & $9.12 \mathrm{e}$ \\
\hline $9 c, 12 c-18: 2$ & $8.41 \mathrm{~b}$ & $8.36 \mathrm{~b}$ & $9.19 c$ & n.d. & $8.93 b c$ & $10.91 d$ & $7.46 \mathrm{a}$ & $11.51 \mathrm{~d}$ \\
\hline $9 \mathrm{c}, 11 \mathrm{t}-18: 2$ (CLA) & $0.38 \mathrm{a}$ & $0.26 \mathrm{a}$ & $0.32 \mathrm{a}$ & n.d. & $0.20 \mathrm{a}$ & $0.65 b$ & $2.01 \mathrm{c}$ & $0.33 a$ \\
\hline 19:0 & $0.01 \mathrm{a}$ & n.d. & n.d. & n.d. & n.d. & n.d. & n.d. & n.d. \\
\hline $19: 1$ & $0.04 \mathrm{~b}$ & $0.02 \mathrm{a}$ & $0.06 \mathrm{c}$ & n.d. & $0.01 \mathrm{a}$ & $0.04 \mathrm{~b}$ & n.d. & $0.03 b$ \\
\hline 9,10-P-19:0 (CPFA) & n.d. & $0.01 \mathrm{a}$ & n.d & n.d. & n.d. & $0.02 b$ & n.d. & $0.01 \mathrm{a}$ \\
\hline $20: 0$ & $0.02 b$ & $0.01 \mathrm{a}$ & $0.03 c$ & n.d. & $0.01 \mathrm{a}$ & $0.03 c$ & n.d. & $0.04 \mathrm{~d}$ \\
\hline $22: 0$ & $0.01 \mathrm{a}$ & n.d. & $0.01 \mathrm{a}$ & n.d. & $0.01 \mathrm{a}$ & n.d. & n.d. & $0.01 \mathrm{a}$ \\
\hline Total saturated & 81.86 & 80.55 & 79.96 & 98.77 & 81.41 & 74.58 & 78.90 & 75.73 \\
\hline Total monounsaturated & 9.34 & 10.83 & 10.53 & 1.23 & 9.47 & 13.85 & 11.63 & 12.45 \\
\hline Total polyunsaturated & 8.80 & 8.61 & 9.51 & 0.00 & 9.12 & 11.56 & 9.47 & 11.84 \\
\hline
\end{tabular}

* The shorthand notation of fatty acids from AOCS lipid library was used.

Table 3

Sterol and policosanols content of BSF oil obtained from BSF2 samples (data are expressed as relative percentage on the unsaponifiable fraction except for the total, expressed as $\mathrm{g} / 100 \mathrm{~g}$ fat).

\begin{tabular}{lllll}
\hline & BSF2bl T0 & BSF2bl T1 & BSF2fr T0 & BSF2fr T1 \\
\hline Policosanols & $1,1 \mathrm{a}$ & $1,5 \mathrm{~b}$ & $1,0 \mathrm{a}$ & $1,9 \mathrm{c}$ \\
Cholesterol & $1,3 \mathrm{a}$ & $1,2 \mathrm{a}$ & $1,2 \mathrm{a}$ & $1,5 \mathrm{a}$ \\
Campesterol & $22,5 \mathrm{a}$ & $23,7 \mathrm{a}$ & $23,7 \mathrm{a}$ & $22,8 \mathrm{a}$ \\
Stigmasterol & $6,3 \mathrm{a}$ & $4,3 \mathrm{~b}$ & $6,2 \mathrm{a}$ & $6,4 \mathrm{a}$ \\
Beta-sitosterol & $61,1 \mathrm{a}$ & $59,7 \mathrm{a}$ & $60,1 \mathrm{a}$ & $58,0 \mathrm{a}$ \\
Stigmastanol & $7,2 \mathrm{a}$ & $9,2 \mathrm{~b}$ & $8,1 \mathrm{~b}$ & $9,2 \mathrm{~b}$ \\
Total (g/100g & $0,46 \pm 0.03 \mathrm{~b}$ & $0,33 \pm 0.05 \mathrm{c}$ & $0,52 \pm 0.04 \mathrm{~b}$ & $0,81 \pm 0.03 \mathrm{a}$ \\
\multicolumn{1}{c}{ fat) } & & & &
\end{tabular}

Values followed by different letters within one row are significantly different $(\mathrm{p}<.05) ; \mathrm{n}=3$.
Saraiva, Aubourg, Vázquez, \& Torres, 2015), but it was never reported for insects and for BSF oil. It is likewise known that the lipolysis activities in foods is generally limited to a minor fraction of lipids. For example in some fishes, free fatty acids reach $3 \%$ after 12 months of frozen storage (Romotowska, Karlsdóttir, Gudjónsdóttir, Kristinsson, \& Arason, 2016). In ripened cheeses, the content of free fatty acids is limited to $1-5 \%$, according to the ripening time and production technology (Addis et al., 2015; McCarthy, Wilkinson, Kelly, \& Guinee, 2017). Also in vegetable oils, the natural content of free fatty acids is generally limited to amount $<10 \%$, for example, $2.3-6.7 \%$ in palm oil, according to Saad et al. (2006). Therefore, the free fatty acids content in BSF, reaching in some samples almost the total of the lipid fraction, represents an exceptional case, and this is the first report highlighting this strong lipolysis in insects.

Data seem to be in agreement with the high concentration (and thus likely the high enzymatic activity) of the lipase enzyme present in BSF

Table 4

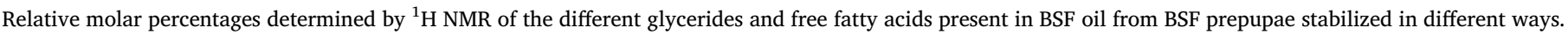

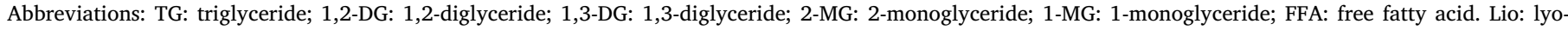
philized; fr: frozen; bl: blanched. Values followed by different letters within one row are significantly different $(\mathrm{p}<.05)$; $\mathrm{n}=3$.

\begin{tabular}{|c|c|c|c|c|c|c|c|}
\hline & BSF1lio & BSF1fr & BSF1fr whole & BSF2bl T0 & BSF2bl T1 & BSF2fr T0 & BSF2fr T1 \\
\hline $1,2 \mathrm{DG}$ & $1.01 \mathrm{a}$ & $1.47 \mathrm{c}$ & $11.43 \mathrm{e}$ & $0.54 b$ & $1.08 \mathrm{a}$ & $5.52 \mathrm{~d}$ & $2.14 c$ \\
\hline $2 \mathrm{MG}$ & $0.11 b$ & $0.03 b$ & $0.47 \mathrm{a}$ & nd & $0.23 c$ & $0.06 \mathrm{~b}$ & $0.13 \mathrm{~b}$ \\
\hline $1,3 \mathrm{DG}$ & $0.17 \mathrm{~d}$ & $0.34 \mathrm{~cd}$ & $1.76 \mathrm{a}$ & $0.46 \mathrm{c}$ & $0.46 c$ & $0.79 b$ & $0.46 c$ \\
\hline $1 \mathrm{MG}$ & $1.5 \mathrm{~b}$ & $0.49 c$ & $2.1 \mathrm{a}$ & nd & $0.23 \mathrm{~d}$ & $0.49 c$ & $0.44 \mathrm{c}$ \\
\hline TG & $0.14 \mathrm{~d}$ & $5.26 c$ & $5.6 \mathrm{c}$ & $99.01 \mathrm{a}$ & $97.97 \mathrm{a}$ & $58.01 \mathrm{~b}$ & $6.38 c$ \\
\hline FFA & $97.09 \mathrm{a}$ & $92.42 \mathrm{a}$ & $78.63 \mathrm{~b}$ & $\operatorname{tr}$ & $\operatorname{tr}$ & $35.14 \mathrm{c}$ & $90.45 a$ \\
\hline Total & 100 & 100 & 100 & 100 & 100 & 100 & 100 \\
\hline
\end{tabular}




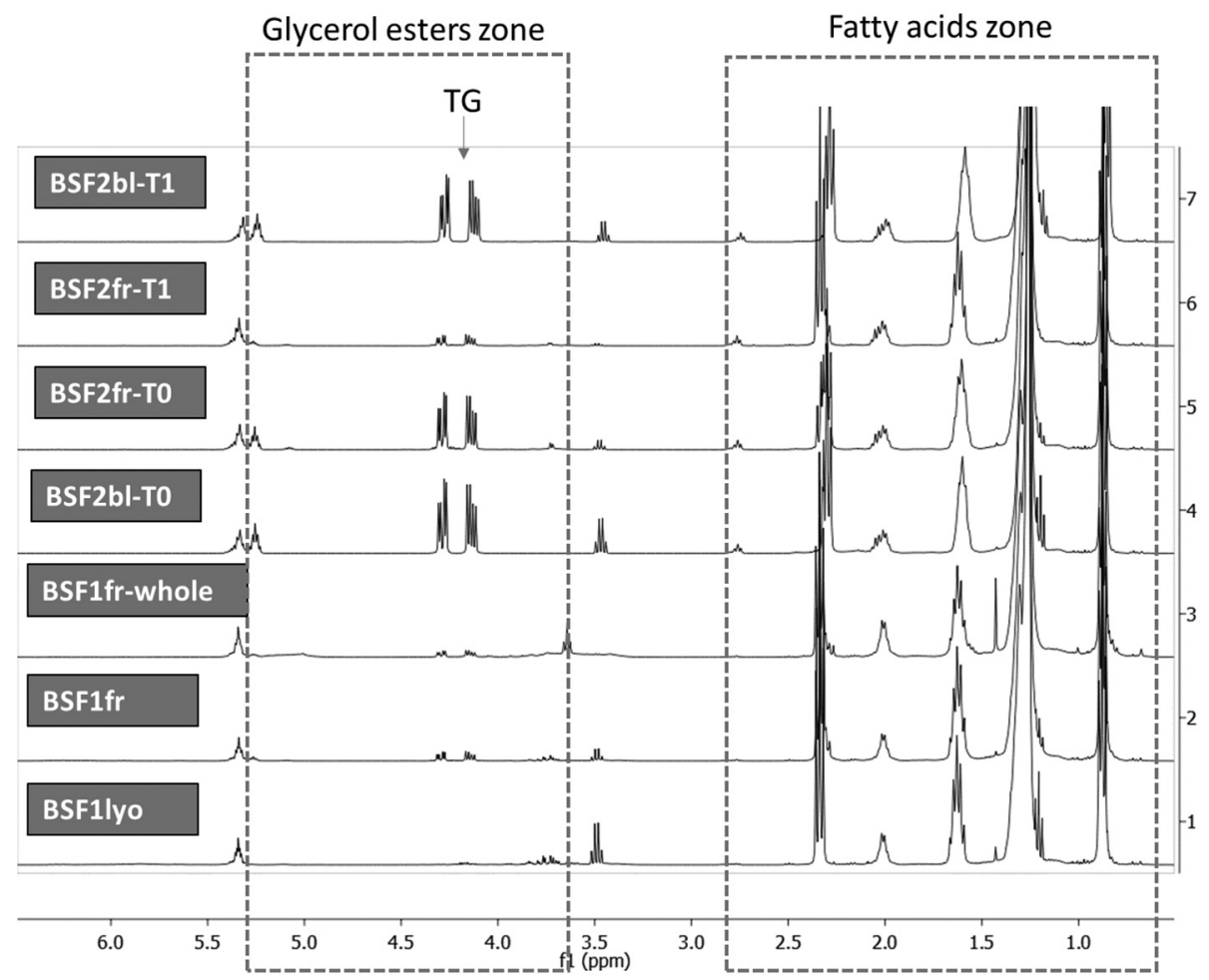

Fig. 1. ${ }^{1} \mathrm{H}$ NMR spectra $\left(\mathrm{CDCl}_{3}, 400 \mathrm{MHz}\right)$ of lipid fraction of the BSF prepupae killed and stored in different ways.

(Kim et al., 2011).

\subsection{Sterol and policosanol profile}

Sterol and policosanols was determined in the unsaponifiable matter of the same samples characterized for fatty acid profile. Results are reported in Table 3 as percentage of each sterol and polycosanols respect to total sterol/policosanol. The absolute amount of the total sterols/policosanols of BSF fat was also reported as $\mathrm{g} / 100 \mathrm{~g}$ fat.

Data showed that sterols normally characteristic of plants (phytosterols) are the main component of BSF sterol fraction, being $\beta$-sitosterol, and campesterol the most represented, while cholesterol is present in low amount. These results are consistent with what reported by Ushakova et al. (2016). These data suggest that larvae of black soldier fly grown on plant substrate do not metabolize completely plant sterols but store them as part of their lipid content. In fact, in animals phytosterols are not efficiently absorbed and their amount respect to cholesterol is normally around 5\% (Ling \& Jones, 1995). In this case the high amount of phytosterols in the insect body (deriving from the vegetable substrate on they were grown) suggests that they are probably absorbed, not metabolized and stored. The low cholesterol amount combined with high phytosterols levels make the BSF fat (grown on vegetable substrates) slightly healthier as compared to other animal fats, because phytosterols have been demonstrate to reduce LDL cholesterol (EFSA, 2008). Together with sterols, in the same GC-MS chromatographic run it was possible to identify six policosanols, i.e. long chain primary alcohols, characterized according to their mass spectra and by comparison with literature data (Caligiani et al., 2010). The most abundant policosanols in BSF fat are represented by C22 (docosanol) and C28 (octacosanol) followed by C24 (tetracosanol), C26 (hexacosanol), C23 (tricosanol) and C25 (pentacosanol). They are generally present in nature as ester with fatty acids, therefore their presence suggests a possible waxy component in BSF. Due to the analytical method adopted, involving the saponification step, it is not possible to know the ratio between free and esterified form. Policosanols are used as dietary supplements with some claimed physiological activities: reduction platelet aggregation, increased athletic performance, reduction in LDL cholesterol levels, and increased HDL cholesterol levels in blood. Therefore, their presence in BSF fat might contribute to a slight better lipid profile respect to animal fats. Their real efficacy, however, is still matter of questioning (Kassis, Marinangeli, \& Jones, 2009).

Regarding the effect of the BSF killing method and storage on unsaponifiable profile, data were in perfect agreement with those obtained on fatty acid profile: the sterol content was similar in all the samples, except sample subjected only to freezing treatment after two months of storage (BSF2fr-T1), which showed significantly higher sterol amounts $(0.81 \mathrm{~g} / 100 \mathrm{~g}$ fat). The explanation for this result is still matter of investigation, but probably has to be searched as well in the global change occurring in the lipid profile of BSF prepupae not thermally treated. The difference observed is only quantitative, because the relative percentages of each sterol are very similar in all samples.

\subsection{Lipid classes distribution determined by ${ }^{1} \mathrm{H} N \mathrm{NR}$}

Due to the high amount of free acidity found in some BSF oil samples and the differences in fatty acids and sterols profiles, a deeper investigation on the lipid classes' distribution was finally performed. To obtain quantitative data on the relative amount of each lipid class, a simple procedure based on ${ }^{1} \mathrm{H}$ NMR spectroscopy was used, adapted for the identification and quantitation of different lipid species in BSF oil. The method offers a rapid assessment of content and composition of major lipid classes, including triacylglycerols (TG), diacylglycerols, (DG), monoacylglycerols (MG) and free fatty acid (FFA), as previously reported (Nieva-Echevarría, Goicoechea, Manzanos, \& Guillén, 2014; Nieva-Echevarría, Manzanos, Goicoechea, \& Guillén, 2017; Nuzzo et al., 2013).

The ${ }^{1} \mathrm{H}$ NMR spectra of the samples considered (see paragraph 2.7) are reported in Fig. 1. From a simple visual inspection of the spectra, it emerges the extremely different relative abundance of the triacylglycerol signals, which in some samples resulted to be much lower than in others. Beside triacylglycerols (TG), also the other classes of fatty acids 
esters (1-MG, 2-MG, 1,2-DG, 1,3-DG) showed diagnostic signals that could be selected as NMR markers with no interference by other compounds. The quantitative molar proportions of the different acyl groups and of some minor components present in the lipid extracts are reported in Table 4.

NMR data confirmed that in all cases where only freezing was applied, free fatty acids accounted for most of the lipid content. The only sample showing low free fatty acids and a stable lipid fraction during storage was BSF2bl, the one subjected to blanching treatment. This clearly indicates that thermal treatment inactivates endogenous lipase enzymes. Lipase are instead activated during the slow killing by freezing, and they remain active after the death. Data suggest also that lipase action occurs quickly during the killing by freezing: in fact, BSF2fr sample presents high molar percentages of free fatty acids (34.14\%) also when analysed at T0, immediately after killing. After two months of storage the free fatty acids reached a molar percentage of $>90 \%$ (BSF2fr-T1), which was further slightly increased in prolonged storage (BSF1fr) and also when samples were stored after freezedrying (BSF1lyo), due to the residual activities of lipase after death and during frozen storage. An effect of sample grinding was also observed: BSF1lyo sample, stored in grinded form, presented the higher amount of free fatty acids (97\%) and negligible amounts of intact triacylglycerols $(0.14 \%)$. The grinding effect seems to occur also instantaneously during sample preparation: lipids extracted from BSF1fr sample either after grinding or directly on the whole larva, showed a higher amount of free fatty acid in the former case $(92.42 \%$ vs. $78.63 \%)$

In general, the ${ }^{1} \mathrm{H}$ NMR results definitively confirmed that the BSF lipid fraction composition strongly depends on the BSF killing methods and on the storage conditions.

The lipid classes distribution is important to evaluate the possible uses of BSF oil.

Currently the most explored application for BSF oil is biodiesel, and it has then been proposed as a valid alternative to vegetal biodiesel (Dias et al., 2009; Fu et al., 2015; Leong et al., 2016). The high concentration of medium chain saturated fatty acids and the low concentration of polyunsaturated fatty acids make the BSF oil an ideal substrate for the production of high quality biodiesel with low viscosity and oxidative stability (Zheng et al., 2012). The production of biodiesel from vegetable and animal oils requests an acid-catalyzed esterification of free fatty acids (to reduce fatty acidity) and an alkaline-catalyzed trans esterification (Marchetti, Miguel, \& Errazu, 2007; Meher, Vidya Sagar, \& Naik, 2006). Due to this specific step of production, the lipolysis process demonstrated in this work on BSF larvae killed by freezing seems to be not critical in the case of the use of BSF oil for biodiesel production, as in any case a reaction of methylation of acylglycerol is needed. Of course, the knowledge of the ratio between glycerol-bound and free fatty acids is important to correctly define the reaction conditions for methylation.

On the other hand, a more economically advantageous use of BSF oil could be in the food/feed or pharmaceutical industries. The total lipid profile of BSF prepupae (Table 2) shows characteristics similar to some vegetable oils for food uses. In particular, the percentage of lauric acid and the global fatty acids profile make BSF oil comparable to coconut oil and palm kernel oil (Lira et al., 2017). These tropical oils, being highly saturated, have many applications in the alimentary industry (e.g. frying oils), but also in the soap industries, pharmaceuticals, cosmetics, plastics etc. (Gopala Krishna, Gaurav, Ajit Singh, \& Prasanth Kumar, 2010). BSF oil could be used in similar applications. Food lipids (both of animal and vegetal origins) are mainly constituted by triacylglicerols and when the oil/fat acidity is higher than $2 \%$, a neutralization step is needed. Therefore, the detailed lipid classes profiling obtained in this study suggests that a thermal pre-treatment on living larvae/prepupae is mandatory to inactivate lipase and preserve an intact lipid fraction suitable for eventual food applications.

\section{Conclusions}

The use of insects as feed is allowed in EU for aquaculture and with the new EU regulation on Novel Foods it is likely that in short times insects will be authorized also as food. Therefore, the use of insects as food, despite could be controversial, is a forthcoming event that cannot be neglected by food scientists. Insects as Novel Foods need authorization from EFSA, whose opinions are generally based on the examination of food composition data. In this context, the data collected in this paper about the lipid fraction gain particular importance. The detailed lipid profiling is the basis of new knowledge about BSF composition according to the killing method and storage. In particular, our data showed that a thermal pre-treatment (killing by blanching) is needed to inactivate lipase activity and preserve an intact lipid fraction to be used for eventual food applications. On the contrary, a strong lipolysis process seems to occur when killing by freezing is applied, which could be not critical in the case of the use of BSF oil for biodiesel production, as in any case a reaction of transmethylation of acylglycerol is needed.

The high rate of lipolisis in non-thermally inactivated BSF prepupe indicates a high lipase activity inside the insect biomass, possibly even stimulated by the cold environment. This aspect needs to be further investigated and the lipid detailed characterization extended to other insect species to verify if a similar behaviour occurs.

\section{Role of authors}

AC, conception and design, interpretation of data, drafting the article; AM, ${ }^{1} \mathrm{H}$ NMR analysis and interpretation of the data; AS, FB, VL, acquisition of GC-MS data, interpretation of the results, statistical analysis; LM, contribution to conception, critical revision; SS, contribution to conception and experiment design, critical revision and final approval of the version to be published.

\section{Conflict of interest}

The authors declare no conflict of interest.

\section{Funding sources}

This research did not receive any specific grant from funding agencies in the public, commercial, or not-for-profit sectors.

\section{Appendix A. Supplementary data}

Supplementary data to this article can be found online at https:// doi.org/10.1016/j.foodres.2018.08.033.

\section{References}

Addis, M., Fiori, M., Riu, G., Pes, M., Salvatore, E., \& Pirisi, A. (2015). Physico-chemical characteristics and acidic profile of PDO pecorino Romano cheese: Seasonal variation. Small Ruminant Research, 126, 73-79.

AOAC Official Method of Analysis (2006). Method 991.36. Fat (Crude) in meat and meat products (18th Ed.). Gaithersburg, MD: AOAC Int.

Balzan, S., Fasolato, L., Maniero, S., \& Novelli, E. (2016). Edible insects and young adults in a north-east Italian city: An exploratory study. British Food Journal, 118(2), 318-326.

Barroso, F. G., de Haro, C., Sánchez-Muros, M. J., Venegas, E., Martínez-Sánchez, A., \& Pérez-Bañón, C. (2014). The potential of various insect species for use as food for fish. Aquaculture, 422, 193-201.

Berner, D. (1989). AOCS' 4th edition of methods. Journal of the American Oil Chemists Society, 66, 1749.

Caligiani, A., Bonzanini, F., Palla, G., Cirlini, M., \& Bruni, R. (2010). Characterization of a potential nutraceutical ingredient: Pomegranate (Punica granatum L.) seed oil unsaponifiable fraction. Plant Foods for Human Nutrition, 65(3), 277-283.

Caligiani, A., Marseglia, A., Leni, G., Baldassarre, S., Maistrello, L., Dossena, A., \& Sforza, S. (2018). Composition of black soldier fly prepupae and systematic approaches for extraction and fractionation of proteins, lipids and chitin. Food Research International, $105,812-820$ 
Caparros Megido, R., Sablon, L., Geuens, M., Brostaux, Y., Alabi, T., Blecker, C., ... Francis, F. (2013). Edible insects acceptance by Belgian consumers: Promising attitude for entomophagy development. Journal of Sensory Studies, 29, 14-20.

Cequier-Sanchez, E., Rodriguez, C., Ravelo, A. G., \& Zarate, R. (2008). Dichloromethane as a solvent for lipid extraction and assessment of lipid classes and fatty acids from samples of different natures. Journal of Agricultural and Food Chemistry, 56(12), 4297-4303.

Dias, M. O. S., Ensinas, A. V., Nebra, S. A., Maciel Filho, R., Rossell, C. E. V., \& Wolf Maciel, M. R. (2009). Production of bioethanol and other bio-based materials from sugarcane bagasse: Integration to conventional bioethanol production process. Chemical Engineering Research and Design, 87, 1206-1216.

Diener, S., Studt Solano, N. M., Gutiérrez, F. R., Zurbrügg, C., \& Tockner, K. (2011). Biological treatment of municipal organic waste using black soldier fly larvae. Waste Biomass Valorisation, 2, 357-363.

EFSA (2008). Plant Sterols and Blood Cholesterol. Scientific substantiation of a health claim related to plant sterols and lower/reduced blood cholesterol and reduced risk of (coronary) heart disease pursuant to Article 14 of Regulation (EC) No 1924/2006. The EFSA Journal, 781, 1-12.

Fellows, P. (2009). Food processing technology: Principles and practice. Cambridge: Woodhead Publishing Limited.

Fidalgo, L. G., Saraiva, J. A., Aubourg, S. P., Vázquez, M., \& Torres, J. A. (2015) Enzymatic activity during frozen storage of Atlantic horse mackerel (Trachurus tra churus) pre-treated by high-pressure processing. Food and Bioprocess Technology, 8 , 493-502.

Folch, J., Lees, M., \& Sloane Stanley, G. H. (1957). A simple method for the isolation and purification of total lipides from animal tissues. Journal of Biological Chemistry, 226(1), 497-509.

Fu, W. J., Chi, Z., Ma, Z. C., Zhou, H. X., Liu, G. L., Lee, C. F., \& Chi, Z. M. (2015) Hydrocarbons, the advanced biofuels produced by different organisms, the evidence that alkanes in petroleum can be renewable. Applied Microbiology and Biotechnology, 99(18), 7481-7494.

Gopala Krishna, A. G., Gaurav, R., Ajit Singh, B., \& Prasanth Kumar, P. K. (2010). Coconut oil: Chemistry, production and its applications-a review. Indian Coconut Journal, 53(3), 15-27.

van Huis, A., Van Itterbeeck, J., Klunder, H., Mertens, E., Halloran, A., Muir, G., \& Vantomme, P. (2013). Edible insects: Future prospects for food and feed security. Edition: FAO forestry paper 171, Publisher: Food and agriculture organization of the United Nations. FAO and Wageningen UR.

ISO 12228-1 (2014). Determination of individual and total sterols contents - Gas chromatographic method - Part 1: Animal and vegetable fats and oils.

ISO 12966-2 (2017). Animal and vegetable fats and oils - Gas chromatography of fatty acid methyl esters- Part 2: Preparation of methyl esters of fatty acids.

Kassis, A. N., Marinangeli, C. P. F., \& Jones, P. J. H. (2009). Reply to the discussion by Sergei V Jargin on evaluation of cholesterol lowering and antioxidant properties of sugar cane policosanols in hamsters and humans. Applied Physiology, Nutrition, and Metabolism, 34, 76-77.

Kim, W., Bae, S., Park, K., Lee, S., Choi, Y., Han, S., \& Koh, Y. (2011). Biochemical characterization of digestive enzymes in the black soldier fly, Hermetia illucen (Diptera: Stratiomyidae). Journal of Asia-Pacific Entomology, 14(1), 11-14.

Kouřimská, L., \& Adámková, A. (2016). Nutritional and sensory quality of edible insects. NFS Journal, 4, 22-26.

Leong, S. Y., Kutty, S. R., Malakahmad, A., \& Tan, C. K. (2016). Feasibility study of biodiesel production using lipids of Hermetia illucens larva fed with organic waste. Waste Management, 47(A), 84-90.

Li, Q., Zheng, L., Cai, H., Garza, E., Yu, Z., \& Zhou, S. (2011). From organic waste to biodiesel: Black soldier fly, Hermetia illucens, makes it feasible. Fuel, 90, 1545-1548.
Li, S., Ji, H., Zhang, B., Tian, J., Zhou, J., \& Yu, H. (2016). Influence of black soldier fly (Hermetia illucens) larvae oil on growth performance, body composition, tissue fatty acid composition and lipid deposition in juvenile Jian carp (Cyprinus carpio var. Jian). Aquaculture, 465, 43-52.

Li, W., Li, Q., Zheng, L., Wang, Y., Zhang, J., Yu, Z., \& Zhang, Y. (2015). Potential biodiesel and biogas production from corncob by anaerobic fermentation and black soldier fly. Bioresource Technology, 194, 276-282.

Ling, W. H., \& Jones, P. J. H. (1995). Dietary phytosterols: A review of metabolism, benefits and side effects. Life Sciences, 57(3), 195-206.

Lira, G. M., Cabral, C. C. V. Q., de Oliveira, I. B. A., Figueiredo, B. C., Simon, S. J. G. B., \& Bragagnolo, N. (2017). Changes in the lipid fraction of king mackerel pan fried in coconut oil and cooked in coconut milk. Food Research International, 101, 198-202.

Marchetti, J. M., Miguel, V. U., \& Errazu, A. F. (2007). Possible methods for biodiesel production. Renewable and Sustainable Energy Reviews, 11, 1300-1311.

McCarthy, C. M., Wilkinson, M. G., Kelly, P. M., \& Guinee, T. P. (2017). A profile of the variation in compositional, proteolytic, lipolytic and fracture properties of retail Cheddar cheese. International Journal of Dairy Technology, 70(4), 469-480.

Meher, L. C., Vidya Sagar, D., \& Naik, S. N. (2006). Technical aspects of biodiesel production by transesterification-a review. Renewable and Sustainable Energy Reviews, 10 , 248-268.

Nieva-Echevarría, B., Goicoechea, E., Manzanos, M. J., \& Guillén, M. D. (2014). A method based on ${ }^{1} \mathrm{H}$ NMR spectral data useful to evaluate the hydrolysis level in complex lipid mixtures. Food Research International, 66, 379-387.

Nieva-Echevarría, B., Manzanos, M. J., Goicoechea, E., \& Guillén, M. D. (2017). Changes provoked by boiling, steaming and sous-vide cooking in the lipid and volatile profile of European sea bass. Food Research International, 99, 630-640.

Nuzzo, G., Gallo, C., D'Ippolito, G., Cutignano, A., Sardo, A., \& Fontana, A. (2013). Composition and quantitation of microalgal lipids by ERETIC ${ }^{1} \mathrm{H}$ NMR method. Marine Drugs, 11, 3742-3753.

Ramos-Bueno, R. P., González-Fernández, M. J., Sánchez-Muros-Lozano, M. J., GarcíaBarroso, F., \& Guil-Guerrero, J. L. (2016). Fatty acid profiles and cholesterol conten of seven insect species assessed by several extraction systems. European Food Research and Technology, 242(9), 1471-1477.

Ramos-Elorduy, J. (1997). Insects: A sustainable source of food? Ecology of Food and Nutrition, 36, 247-276.

Romotowska, P. E., Karlsdóttir, M. G., Gudjónsdóttir, M., Kristinsson, H. G., \& Arason, S. (2016). Influence of feeding state and frozen storage temperature on the lipid stability of Atlantic mackerel (Scomber scombrus). International Journal of Food Science and Technology, 51, 1711-1720.

Saad, B., Ling, C. W., Jab, M. S., Lim, B. P., Ali, A. S. M., Wai, W. T., et al. (2006). Determination of free fatty acids in palm oil samples using non-aqueous flow injection titrimetric method. Food Chemistry, 102, 1407-1414.

Surendra, K. C., Olivier, R., Tomberlin, J. K., Jha, R., \& Khanal, S. K. (2016). Bioconversion of organic wastes into biodiesel and animal feed via insect farming. Renewable Energy, 98, 197-202.

Ushakova, N. A., Brodskii, E. S., Kovalenko, A. A., Bastrakov, A. I., Kozlova, A. A., \& Pavlov, D. S. (2016). Characteristics of lipid fractions of larvae of the black soldier fly Hermetia illucens. Doklady Biochemistry and Biophysics, 468, 209-212.

Vandeweyer, D., Lenaerts, S., Callens, A., \& Van Campenhout, L. (2017). Effect of blanching followed by refrigerated storage or industrial microwave drying on the microbial load of yellow mealworm larvae (Tenebrio molitor). Food Control, 71, 311-314.

Zheng, L., Hou, Y., Li, W., Yang, S., Li, Q., \& Yu, Z. (2012). Biodiesel production from rice straw and restaurant waste employing black soldier fly assisted by microbes. Energy, 47, 225-229. 